\title{
A Clash of Names: The Terminological Morass of a Toponym Class
}

\author{
JAN TENT \\ Australian National University, Australia \\ DAVID BLAIR \\ Australian National Placenames Survey
}

There are place names all around the world formed by a combination of two elements, a specific and a generic, both of which refer to the same geographic feature type. A typical pattern is for an indigenous generic functioning as a specific to precede a matching introduced generic. For example: Ohio River $<$ Iroquoian Ohio 'Great River' + River, and Lake Rotorua < Māori roto 'lake' + rua 'two/ second' ('Second Lake') + Lake. Such toponyms, though not overall numerous, nevertheless occur often enough to warrant being recognized as a distinct class of place names. The literature provides no adequate or consistent term for this pattern: the various attempts clash with each other, and all fail to address the concept effectively. This article aims to address this situation.

KEYWORDS tautological (place) names, tautonyms, reduplicated names, bilingual place names, epexegesis, macaronic duplex toponym

\section{Introduction}

It is notable that place names which represent features of the natural environment commonly have an internal grammatical structure consisting of a sequence of the elements specific + generic (usually, but not invariably, appearing in that order). ${ }^{\mathrm{I}}$ In one particular context, that grammatical structure is often seen to take an unusual turn.

When speakers of different languages come into contact, their languages often influence one another. The most common phenomenon is that of copying (after Crowley I997, 240-42), commonly referred to as borrowing. ${ }^{2}$

It should not come as a surprise that the copying process can also apply to place names. It is only natural for visitors and explorers (or more likely invaders and colonizers) to ask local indigenous peoples: "What do you call this place/river/bay/ mountain?" Indeed, place names are likely to be one of the first lexical items copied. 
As Sanders $(2016,540)$ points out, these are not always understood by the copiers. For this reason the co-joining of a place name or generic from one language and that of a place name generic from another is a not uncommon result of language contact. In other words, a place name (or place-name element) from language $X$ is copied (without necessarily knowing its meaning) into language $Y$, after which a standard descriptor (that is, the generic element) is added from the copying language $(Y)$. As Sanders observes, "place-names containing elements from more than one language are of special interest to contact onomastics" (548). Examples of such confluences include:

- Mount Maunganui (NZ) literally 'Mount Big Mount', from the Māori maunga 'mountain' + nui 'large, big, important'.

- Beechhurst Holt Wood (UK) lit. 'Beechwood Wood Wood', from AngloSaxon hurst 'wood' + holt 'wood, grove, copse'.

- River Avon (Wales) lit. 'River River', from Brythonic, spelled afon 'river' in modern Welsh.

- Mississippi River (USA) lit. 'Great River River', from French Messipi from Algonquian Misi-ziibi 'Great River'.

- Laguna Lake (California) lit. 'Lake Lake', from Spanish laguna 'lake'.

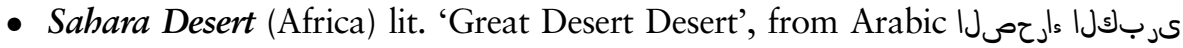
'aș-Saḥrā, al-Kubrā' 'the Great Desert'.

- Mount Fujiyama (Japan) lit. 'Mount Mount Fuji', from Japanese yama 'mountain'.

- Saaremaa Island (Estonia) lit. 'Isle's land Island'.

- Uluinakauvadra Mountain (Fiji) lit. 'Nakauvadra Mountain Mountain', from ului 'mountain'.

- Dreketi River (Fiji) lit. 'River River', from obsolete dreketi 'river'.

- Tore Lake (Fiji) lit. 'Lake Lake', from tore 'lake'.

- Timor Leste lit. 'East East', from Indonesian and Malay timur 'east' + Portuguese Leste 'east'.

There are plentiful examples of such toponyms all around the world. Many such toponyms, (Mount Fujiyama and Sahara Desert, for instance) are in fact exonyms and are not used in the country in which they are located. ${ }^{3}$

In Australia there are also a number of such blended toponyms - confluences of generic elements from Indigenous Aboriginal languages and English. Interestingly, as with many other examples from around the world, these also often name water features: ${ }^{4}$

- Cowal Swamp, from Wiradjuri cowal 'swampy hollow'; Gamilaraay, Yuwaalaraay, and Yuwaalayaay gawal 'watercourse, swamp, billabong' (also used as a generic for the features SWAMP, STREAM, LAGOON, LAKE, and WATERHOLE) (Nash 2008).

- Warrambool Watercourse, from Gamilaraay, Yuwaalaraay, and Yuwaalayaay warrambool 'watercourse (overflow channel), stream'.5

- Beerie Gnamma Hole, Fig Tree Gnamma Hole, from Nyungar gnamma 'rock hole'. 
- Billabong Creek, from [contested] Wiradjuri bilaban, 'watercourse that runs only after rain', from [contested] bila 'river' + bong/bung 'dead'.

- Gilgai Waterhole, from Kamilaroi and Wiradjuri gilgai 'water hole’.

Nicolaisen (1975) examines the phenomenon in his article "Place-Names in Bilingual Communities" and surveys the copying of place names in bilingual Gaelic communities in Scotland. He lists a number of processes involved in the transfer of place names or place-name elements from one language to another. He claims place names " $[\ldots]$ are exposed to more interference in their transfer from one language to another than are more 'ordinary' loan words" (I67), but provides no evidence for this. However, a significant effect of this onomastic transfer is "lexical meaninglessness and morphological opacity" in both the donor and copying language. The toponymic examples given above are tangible examples of this copying process.

\section{Current status: a critical assessment}

Curiously, we have found little, if any, explicit mention of such toponyms in the publications of any place-naming agency (nationally or internationally). ${ }^{6}$ They are normally not named as a class, or if they are, the terms are inconsistent, inaccurate, non-standardized, or in general use. The only agency that makes mention of such toponyms is the Geographical Names Board of Canada (20II). In its Principles and Procedures for Geographical Naming 20I I, Principle I 2 - Generic Terminology (page I 8) it states:

A geographical name usually includes both a specific and a generic element. The generic term in a newly approved geographical name should be appropriate to the nature of the feature. Its position in the name should be dictated by euphony and usage. The generic term will be recorded in English, in French or in an Aboriginal language by the names authority concerned.

But more specifically, under item 8 of Principle I2:

Occasionally a name of Aboriginal origin has fused with the specific, a generic term that is similar in meaning to the French or English generic of the toponym. Examples are Mississippi River (Ont.), Pekwawinneepi Creek (Man.) and Lac Matonipi (Que.). Names such as these are quite acceptable.

A similar policy, though less specific, is outlined in the United States Board on Geographic Names Principles, Policies, and Procedures: Domestic Geographic Names document $(2016,18)^{7}$ :

The U.S. Board on Geographic Names recommends the use of generic terms with names derived from Native American languages that are easily understood by the general public and are common to the areas in which the names are applied. This policy applies even though the Native American names may already contain generic elements.

Although they do not give this toponym type a specific name, we do welcome the fact the GNBC and USBGN acknowledge and accept the concept. These are the only instances we have been able to find where acknowledgement is given to the confluence of two languages in a toponym. 
There has also been little mention of these toponym types in general onomastic and toponymic literature. However, authors who do report on them include: Borgmann (I973), Grant (2008), Kadmon (2000b), Nicolaisen (I975), Nuessel (1992), Puder (2009), Room (1996), and Sanders (2016). These authors use a variety of terms to describe these toponyms, none of which we believe captures their true nature and essence. In the following sections we review these terms and then propose what we believe to be a more fitting term.

\section{Tautological (place) names}

From a traditional standpoint, it has been said these place names are "tautologous": that is, the specific and the generic element refer to the same thing-the tautology generally being obscured either by the passage of time and/or by linguistic ignorance/confusion. The Oxford English Dictionary (I989) (OED) defines tautology as an " $[\mathrm{u}]$ nnecessary repetition, usually in close proximity, of the same word, phrase, idea, argument, etc. Now typically: the saying of the same thing twice in different words $[\ldots]$, generally considered to be a fault of style" or "[a] phrase or expression in which a word, phrase, idea, argument, etc., is redundantly repeated, or (now typically) the same thing is said twice in different words."

Room (1996, 96-97) refers to toponyms such as Mississippi River as tautological (place) names. Kadmon (200ob, I29) simply refers to such place names as examples of "tautology." To Room's credit, he adds to his definition that they are "names comprising of words or elements of identical meaning in different languages." Room gives the example: Pendle Hill lit. 'Hill-hill Hill' from Celtic penn 'hill' + Old English byll 'hill' + Modern English Hill. To describe a place name as tautological may usefully point to the historical process by which the toponym has reached its current form, but it is misleading as a label for the class of toponyms under consideration: they do not currently display "unnecessary repetition" or "redundancy."

\section{Tautonyms}

Borgmann (1973) uses the term tautonym for toponyms such as Paw Paw (US-MI), Sing Sing (US-NY), and Walla Walla (US-WA), as well as for the American Sāmoan Pago Pago and Iliili. ${ }^{8}$ He includes in this set names such as New York, New York and Illinois, Illinois. Puder (2009) also uses the term in this manner, as does Grant (2008), who also uses it synonymously with reduplication among others. Room $(1996,97)$ likewise uses this particular term, saying a tautonym is "a name [...] that repeats a word or element." He gives examples such as the anthroponyms Donald Donaldson, William Williams; and the toponyms Dumdum [sic] (India) and Wagga Wagga (Australia). ${ }^{9}$ Strictly speaking, these toponyms do not consist of two words that refer to the same thing. The two elements form the name itself; there is no repetition of the meaning in the generic and specific elements. In other words, there is no "doubling" 
of the meaning. These authors have rather indiscriminately applied the term seemingly based solely on the repetition of the orthographic form.

Why is tautonym not a suitable term for the class of toponyms we are considering?

One reason is that its morphology implies "tautology," and we believe it would be unwise to use a term which inevitably links our class of toponyms to the pejorative sense of "tautology" that the OED records as present-day usage.

A second reason is that the term tautonym is already used in two different contexts which are distinct from our specific/generic toponymic combination. One is the use by Borgmann and others (however unwisely) for names-not necessarily place names - which contain simple repetition within them. Secondly, the term is used in biology as a scientific binomial name "in which exactly the same word is used for both genus and species" (OED). That is, names of fauna in which the same word from the same language is used, for example:

- the red fox-Vulpes vulpes

- the greenfinch-Chloris chloris

- the black rat-Rattus rattus

- the gorilla-Gorilla gorilla

- the European badger-Meles meles

The coining of scientific names is a purposeful, systematic formal process, using a single language to construct these tautonyms. It is quite distinct from the processes of language contact which generate toponyms such as Fiji's Uluinakauvadra Mountain, and to introduce a term from scientific binomial classification for a class of toponyms of a different morphological character is misleading and unhelpful.

\section{Reduplicated names}

A third term sometimes used as a label for our phenomenon is reduplication. ${ }^{\text {Io }}$ This is generally understood to be a morphological process, as defined by Mattes $(2007,4)$ : “[ [.. ] a linguistic form which contains systematic non-recursive repetition of phonological material for morphological or lexical purposes." It operates by repeating, exactly or with a slight change, the whole word, its root or stem (or part of it). But unlike binomial scientific tautonyms, it is used to convey grammatical functions, such as plurality, intensification, the diminutive, some other grammatical function, or in lexical derivation to create neologisms. Reduplication is found in a great number of languages (notably Austronesian languages), and often follows a complex process. ${ }^{\text {I }}$ Once again, only a single language is involved, and the process is purposeful, systematic, and strictly rule-governed. A few examples of this process will suffice here:

- Dakota hãska 'tall' (singular) gives rise to hãskaska 'tall' (plural) (reduplication of the -CCV suffix). 
- Malay rumah 'house' (singular) gives rise to rumab $^{2}$ (i.e. rumah-rumah) 'houses' (plural).

- Boumaa Fijian cula /ðula/ 'to sew' gives rise to culacula /ðulaðula/ 'to sew for a period'.

- Standard Fijian dredre / ${ }^{\mathrm{n}} \mathrm{dre} \mathrm{n}^{\mathrm{n}} \mathrm{dre} /$ 'to laugh'.

- Māori kimo 'to wink' gives rise to kimokimo 'blink, wink repeatedly'.

Room (I996, 87), however, uses the term reduplicated name to refer to toponyms that repeat "in some form (in the same language) the word or name on which it is based," and provides the example Highland Heights. His definition is not precise, and it is not clear why his reduplicated names should not also include Australian toponyms such as Book Book, Woy Woy, Greg Greg, and Mitta Mitta River (all of which are classified by Room as tautonyms). Place names with such internal repetition occur quite frequently in the world's toponymic systems, e.g. Baden-Baden (Germany), Bella Bella (Canada), Bora Bora (French Polynesia), Dum Dum (India), Gode Gode (Tanzania), Lomaloma (Fiji), Safsaf (Israel), Wawa (US-PA), Makemake (a dwarf planet in the Kuiper Belt from the Rapanui language).

Room's restriction of his reduplicated name concept to examples such as Highland Heights is particularly odd in the light of his refusal to include names such as Peter Peterson in that class because "two separate names (forename and surname) are involved" (88). Using the same criterion, one could argue that Highland Heights also does not qualify because two separate names (a specific element and a generic element) are involved. As we have already noted, the specific can be viewed as an equivalent to a "forename," whilst the generic is analogous to a "surname"

Furthermore, several of the examples listed above, but apparently excluded from Room's category, are the result of reduplication in the strict linguistic sense as defined by Mattes. For example, Wagga Wagga is derived from the Australian Wiradjuri language and is purported to mean "place of many crows" - the reduplication indicating the plural form of "crow." Many, if not all, of the Pacific's reduplicated toponyms are the result of historical reduplication. For example, the Fijian Lomaloma is simply the word for 'lagoon' and is historically a derivative of loma'inside.' For other toponyms the original unreduplicated morpheme is now lost, as in the French Polynesian toponym Pukapuka, where there is nowadays no "puka. ${ }^{\mathrm{I} 2}$ Walla Walla (US-WA) is also a reduplication deriving from the Walla Walla people, and expresses the diminutive form, but is also purported to mean 'many waters.' Interestingly, there is also a Walla Walla in Australia, also a true reduplication, which derives from the Wiradjuri word for 'many rocks.'

Other toponyms that have a repeated form, such as Baden-Baden, are not in fact the result of reduplication. The original name of the town was Baden and derives from an earlier plural form of Bad 'bath.' There are several other Badens at hot springs throughout Europe (e.g. Baden near Vienna and Baden near Zürich). The current doubled name arose to distinguish it from the others: Baden-Baden is thus not a reduplication in the strict linguistic sense. We must therefore be cautious of 
labeling toponyms and other names reduplications merely because of their orthographic form. The etymology of the name must be taken into account.

For two reasons, then, we are reluctant to accept reduplication as a label for our category. It is a term which already has an accepted sense in the wider world of linguistic morphology; and within that system of reference, it signals valid grammatical functions rather than unintended semantic redundancy.

\section{Bilingual place names}

Nuessel (1992, 58) refers to our type of place name as bilingual place names. This is an honest and straightforward term, and is based on Nicolaisen's (I975) article "Place-Names in Bilingual Communities" mentioned above. One of the copying processes he lists, (e) $(\mathrm{I} 7 \mathrm{I}-72)$, results in "the receiving language add[ing] a generic of its own which tautologically repeats a generic already contained in the adopted name." Among examples given are:

- Point of Ardnamurchan, in which the English point pleonastically expresses the meaning of Gaelic ard 'promontory'.

- Glenborrodale, in which Gaelic gleann 'valley' repeats Norse dalr 'dale'.

- Ardtornish Point, in which Norse nes 'headland, cape' is combined with Gaelic ard to give, in effect, a double repetition of point.

Nicolaisen does not offer a term for such toponyms; he does, however, use the terms pleonasm and tautology when describing the phenomenon.

Nuessel's use of the term bilingual is not inappropriate, but it encompasses much more than our particular toponymic set: any toponym composed of bilingual elements could properly be thus described. It also has the disadvantage of seeming to imply a current bilingual context for the toponym rather than (as is usually the case) a previous language-contact environment. Nor is the pleonastic nature of the toponym indicated by simply labeling it "bilingual."

\section{Epexegesis}

In a discussion on place names in a language-contact situation, Sanders (2016) outlines the various linguistic adaptations place names may undergo. In the section entitled "Mixed Names-Hybrid Names?" (548-49), she describes the various types of place names that comprise "borrowed" (i.e. copied) words. One of these is the type of place name under discussion in this article. Sanders labels these place names as examples of epexegesis. ${ }^{\mathrm{I}}{ }^{3}$ The OED defines this as: "[t]he addition of a word or words to convey more clearly the meaning implied, or the specific sense intended, in a preceding word or sentence; a word or words added for this purpose." In some instances, this may have been the purpose of adding a generic that echoed the meaning of one already contained in the specific, and in this case the label might be legitimate. However, in many instances (or even 
most) the addition of a generic is the result of not knowing the meaning of the original toponym or realizing there is an embedded generic in the name which has been designated as a specific. As Sanders herself points out, copied names need not necessarily be understood by the adopters: "The names function as labels for places which can be singled out by pointing at them, meaning that only a minimum of communication is needed" (540).

Although Sanders includes this term within her section on language copying, the term epexegesis does not itself capture the confluence of two or more languages; neither does it reflect the usual case that the place name is the result of ignorance of the original meaning. The other terms implied in the section heading, mixed and blended, give no indication of the repetition or pleonasm inherent in the set under discussion.

More generally, epexegesis (like mixing or blending) is the name for a process which may generate our class of toponyms, among others, but it is not a useful label for that class.

\section{Review}

In the toponym class under consideration, place names such as Mississippi River, Warrambool Creek, and Gilgai Waterhole show a generally unwitting duplication of two (or more) generics (with the same meaning) from two (or more) distinct languages. They are quite different in form and derivation than items such as BadenBaden, Vulpes Vulpes, and rumah ${ }^{2}$, and as such deserve an appropriate and specific term to reflect this. The terms discussed above do not adequately fulfill this function. An accurate, clearly defined and delineated toponymic terminology must not only contribute to the standardization of geographical names, but is also essential for the precise classification of toponyms as well as a thorough understanding of placenaming practices in general. It is crucial that terms comprising a terminology of a technical field have monosemous formal definitions, i.e. have single meanings. An important aim in any specialized field is the standardization of its terms (Landau 200I, I05-06) to provide a normative (as well as descriptive) function; failing that, toponymists, geographers, and cartographers will not be able to talk with accuracy and consistency about toponyms and their designations.

So, bearing this in mind, what should we name such toponyms? Below, we propose a possible term to encompass toponyms that comprise generic elements (with the same meaning) from two distinct languages.

\section{A proposed term - macaronic duplex toponym}

The toponyms under consideration here are distinct in that they each consist of two elements (a generic and specific) from two distinct languages (or dialects), and each of those elements refers to the same geographic feature type. We would suggest that an appropriate label for this toponym class should reference its two defining characteristics. 
Firstly, the term macaronic refers to a text using a mixture of languages (usually two). The mixing of languages or dialects during a conversation, known in linguistics as code switching, is the verbal equivalent of this. Macaronic can also be used to refer to hybrid words (i.e. internally macaronic); a good example being TELEVISION from Greek $\tau \tilde{\eta} \lambda \varepsilon$ (têle) 'far' + Latin visio 'seeing' (from videre 'to see').

Macaronic confluences are also very common in copied words that have become fully nativized into the copying language's general vocabulary. This is often manifested through the copying of a word (usually a noun or verb) with the addition of one or more affixes from the morphology of copying language. This is a genuine sign of such words having been fully nativized, not only into the lexicon of the copying language, but also into its morphology and grammar. Three examples will suffice here:

- The Dutch gescreend is the nativized past participle form of English loanword screen 'to vet, evaluate, analyze, filter,' a confluence of English screen $+g e-\ldots-d$ the Dutch past participle affixes.

- The Fiji English lovos, from Fijian lovo 'pit earth oven' + English plural suffix $-s$.

- The Australian English hypocoristic bommie(s), from the Dharruk language bombora 'an off-shore submerged rock over which a wave forms; the wave itself' + hypocoristic form (+ English plural suffix $-s$ ).

Toponyms, as we have seen, can also be macaronic. In addition to the many examples with specific + generic structure already given, names of settlements are often internally macaronic:

- Birdsville, from Middle English byrd, bryd, from Old English brid (in Northumbrian bird) + French ville.

- Castlecrag, from Latin castellum 'castle' + crag from Celtic 'a steep or precipitous rugged rock'.

- Eagleby, from Middle English egle, from Old French egle, aigle, from Latin aquila + Old Scandinavian -by 'farmstead, village'.

- Yarraville, from Boonwurrung \& Woiwurrung yarra 'ever flowing' (name of the river that flows through Melbourne) + French ville.

The term macaronic, itself, seems to have been coined by Teofilo Folengo ("Merlinus Cocaius") in I517, and derives from Modern Latin macaronicus, cognate with Italian macaronelmacaroni (OED). Since the term often has pejorative connotations, and is usually reserved for works where the mixing of two (or more) languages has a humorous or satirical intent or effect, it could be argued that macaronic not be applied to mixed-language texts or expressions of a more serious nature and purpose. However, if we accept for now that there is no inherent reason it not be applied to more serious language use, and if we may indulge the reader, we should like to suggest the term macaronic to indicate one aspect of the toponyms under discussion. 
Secondly, we have chosen the adjective duplex to accompany macaronic because it best expresses the linking together, side by side, of generic elements. The OED provides a useful definition of duplex: "Composed of two parts or elements; twofold," derived from Latin duplex "twofold", from duo "two" + plic "to fold." The accompanying citations illustrate its usage across several fields, including papermaking, biology, biochemistry, and telegraphy. In each of those contexts the key concept is that two elements are conjoined or united side-by-side.

In the context of language-contact toponymy, a similar situation arises. A feature term is semantically repeated, appearing side-by-side in both the specific element and the generic element, to produce what we wish to call a duplex toponym. ${ }^{\mathrm{I}}$

In summary, we can say that the class of toponyms under consideration displays two characteristics: each place name in the class has an internal structure consisting of a specific term and a generic term derived from different languages, and those two terms are linguistic representations of the same generic feature. That is, the toponyms in question are both macaronic and $d u p l e x$.

A particular deficiency of previously-proposed terms for our toponymic class is that they have been superordinates: because they were too generalized or imprecise, they have, either explicitly or by implication, admitted place names to that class which were not truly eligible. The advantage of the term macaronic duplex toponym is that it properly identifies the defining characteristics of the toponymic class under consideration, excluding other instances of place names which are not of that structure.

\section{Concluding remarks}

It is crucial that the term employed to label our particular set of toponyms is monosemous and used consistently. If this is accepted, then we must adopt a terminological approach in determining an appropriate label for such toponyms. In doing so, it should necessarily adhere to the general terminographical principle of working from concept to term (reflecting conceptual distinctions) as opposed to the general lexicographical principle of working from the word to its sense (reflecting semantic distinctions). ${ }^{15}$ None of the terms previously used follow the onomasiological principle; all have been products of a semantic or lexicographic approach and have therefore been deficient in their ability to identify the toponym class we have considered here.

\section{Acknowledgements}

We should like to thank Associate Prof. Paul Geraghty (University of the South Pacific, Suva) and Dennis Nutt (Academic Dean Emeritus, Australian College of Ministries) for their advice and suggestions. Thank you also to the two reviewers for their comments and encouragement. All errors and omissions remain ours.

\section{Disclosure statement}

No potential conflict of interest was reported by the authors. 


\section{Notes}

I. A place name "generic" is akin to a family name (e.g. Bay, Cape, River, Mount, Lake, Valley, etc.). A place name "specific" is analogous to a given name (e.g. Boat Harbor, where "Boat" (the specific) identifies "Harbor" (the generic), which in turn identifies the type of geographic feature named). Sometimes a generic can become a specific, as in The Basin, or Harbor Beach. Place names for nonnatural features (especially those for settlements) commonly consist of a single element acting as the specific: Cairns and Broome. Some place names of this type have a "built-in" generic element, e.g. Newtown, Marrickville, Ashbourne, etc.

2. The term borrowing is problematic because it implies the "borrowed" word will be "returned" at some stage, which is largely not the case. The exceptions are so-called "reborrowings" where a word is copied from language $X$ into language $Y$, and over time changes its meaning in language $Y$, and is subsequently copied back into language $X$ with its new meaning. A nice case is that of the English word threepence which was copied into Fijian and nativized as ciriveni /ðiriveni/. Over time its meaning changed to "miserly." The word ciriveni was then copied back into the variety of English spoken in Fiji with this new meaning (see Tent 200I).

3. An exonym is a place name used by one group that differs from the name used by the people who live there.

4. This is also observed and remarked upon by Nicolaisen (1975, I68).

5. For a very interesting discussion on the meaning and etymology of warrambool, see: Endangered Languages and Cultures (20II) "What's a Warrambool?" www. paradisec.org.au/blog/20I I/o6/what \% E2\% 80\% 99s-a-warrambool.

6. The Committee for Geographical Names in Australasia (I996) (now the Permanent
Committee on Place Names); the International Council of Onomastic Sciences (2012); and Kadmon (2000a).

7. See the link https://geonames.usgs.gov/docs/ Policy_X_I997.pdf on this page for Policy Iо: "Names of Native American Origin." Sec. 7. "Generic Terms Recommended for Geographic Names Derived from Native American Languages."

8. The latter two examples are in fact proper reduplications. See the section Reduplicated names for further explication of this.

9. As with Pago Pago and Iliili, Wagga Wagga is not a tautonym but a reduplication. See the section Reduplicated names for further discussion on this.

Io. Ironically, the term reduplication is itself tautologous!

II. For a more comprehensive discussion of reduplication, see, for example: Downing (2015a, b); Inkelas and Zoll (2005); Inkelas (2008); Marantz (I982).

I 2. In general linguistics, a superscript asterisk (") before a lexical item indicates that it cannot occur in the language. In historical linguistics it indicates a proto-form.

I3. Sanders (20I6) offers a synonym for epexegesis, viz. "tautological addition," though seemingly dismisses this description as somewhat misleading (548). We agree.

I4. Interestingly, in some examples-such as Nicolaisen's Ardtonish Point-the specific element contains a further repetition of the feature term.

I5. Terminography (i.e. the compilation of terminologies) employs an onomasiological approach. That is, it starts from a concept and then determines its name or term. The opposite, the semasiological approach, is employed by lexicographers, and starts with a term and then determines what it means, and to what concepts the term refers. (See: Cabré I999, 37-38; Hartmann and James I998).

\section{References}

Borgmann, Dmitri A. I973. "An Onomastic Study (Part 2).” Word Ways 6. no. 3: I76-I80. Accessed September 29, 2017. http://digitalcommons.butler.edu/wordways/vol6/iss3/I3

Cabré, M. Teresa. I999. Terminology: Theory, Methods and Applications. Amsterdam: John Benjamins B.V.

Committee for Geographical Names in Australasia. I996. Glossary of Generic Terms, Version I.o. Commonwealth of Australia: Intergovernmental Committee on Surveying and Mapping. Accessed October 05, 20I7. www.icsm.gov.au/cgna/glossary_pnames.pdf

Crowley, Terry. 1997. An Introduction to Historical Linguistics. 3rd ed. Auckland: Oxford University Press. 
Downing, Laura. 2015a. "What is Reduplication? Typology and Analysis, Part I/2: The Typology of Reduplication." Language and Linguistics Compass 9. no. I 2: 502-5 I 5.

Downing, Laura. 2015b. "What is Reduplication? Typology and Analysis, Part 2/2: The Analysis of Reduplication." Language and Linguistics Compass 9. no. I2: 516-528.

Geographical Names Board of Canada. 20II. Principles and Procedures for Geographical Naming. Ottawa: Natural Resources Canada. Accessed September 29, 20I7. www.nrcan.gc.ca/sites/www.nrcan. gc.ca/files/earthsciences/pdf/gnames/GNBC_english_accessible.pdf

Grant, Jeff. 2008. "Accidental Tautonyms.” Word Ways 4I. no. 4: 293-296. Accessed October 05, 2017. http://digitalcommons.butler.edu/wordways/vol4 I/iss4/I 5

Hartmann, Reinhard R. K., and Gregory James. 1998. Dictionary of Lexicography. London: Routledge. Inkelas, Sharon and Cheryl Zoll. 2005. Reduplication: Doubling in Morphology. Cambridge University Press.

Inkelas, Sharon. 2008. "The Dual Theory of Reduplication.” Linguistics 46. no. 2: 35 I-40I.

International Council of Onomastic Sciences. 20I2. List of Key Onomastic Terms. Accessed September 29, 20I7. http://www.icosweb.net/index.php/terminology.html

Kadmon, Naftali, ed. 200oa. Glossary of Toponymic Terminology. Version 4, I February, Part I: English. UNGEGN. Accessed September 29, 20I7. http:/www.ngi.be/NL/glossary/glossang-inf.htm

Kadmon, Naftali. 2ooob. Toponymy: The Lore, Laws and Language of Geographical Names. New York: Vantage Press.

Landau, Sidney I. 200I. Dictionaries: The Art and Craft of Lexicography. 2nd ed. Cambridge: Cambridge University Press.

Marantz, Alec. I982. "Re Reduplication.” Linguistic Inquiry I3. no. 3: 435-482.

Mattes, Veronika. 2007. "Types of Reduplication: A Case Study of Bikol." PhD diss., Karl-FranzensUniversität, Graz. Accessed October 05, 20I7. http://reduplication.uni-graz.at/texte/Dissertation_gesamt.pdf

Nash, David. 2008. "Examining the Name Element/Feature Type Cowal." Unpublished paper presented to ANPS/CGNA workshop, Rydges Hotel, Wollongong, Australia, I I October.

Nicolaisen, Wilhelm F. H. I975. "Place-Names in Bilingual Communities." Names 23. no. 3: I67-I74.

Nuessel, Frank. 1992. The Study of Names: A Guide to the Principles and Topics. Westport (CT): Greenwood Press.

Oxford English Dictionary on Historical Principles. I989. London: Oxford University Press.

Puder, Jim. 2009. "More Accidental Tautonyms." Word Ways 42. no. 3: I74-I80. Accessed October 05, 20I7. http://digitalcommons.butler.edu/wordways/vol42/iss3/9

Room, Adrian. 1996. An Alphabetical Guide to the Language of Name Studies. London: The Scarecrow Press Inc.

Sanders, Berit. 20I6. "Names and Language Contact." In The Oxford Handbook of Names and Naming, edited by Carol Hough, 540-553. Oxford: Oxford University Press.

Tent, Jan. 200I. "A Profile of the Fiji English Lexis." English World-Wide 22. no. 2: 2 I I-247.

U.S. Board on Geographic Names. 2016. Principles, Policies, and Procedures / Domestic Geographic Names. Version I.o. Reston (Virginia): Domestic Names Committee. Accessed October 05, 2017. https:/geonames.usgs.gov/docs/DNC_PPP_DEC_20I6_V.r.o.pdf

\section{Notes on contributors}

Jan Tent is a retired academic and current Director of the Australian National Placenames Survey. He is also an Honorary Senior Lecturer at the Australian National University, Canberra, and an Honorary Research Fellow at Macquarie University, Sydney. Jan's onomastic research has mainly concentrated on early European place-naming practices in Australasia, as well as the toponymy of Australia in general.

Correspondence to: Dr Jan Tent, School of Literature, Languages and Linguistics, College of Arts and Social Sciences, Australian National University, Canberra 0200, Australia. Email: jan.tent@anu.edu.au or director@anps.org.au 
David Blair is a retired academic who currently serves research toponymist with the Australian National Placenames Survey. He is also an Honorary Associate at Macquarie University, Sydney. His recent research has focused on theoretical aspects of toponymy, and on the names of Australia's coastal beaches.

Correspondence to: Mr David Blair, Department of Linguistics, Macquarie University, Sydney 2ı09, Australia. Email: David.Blair@mq.edu.au or research@anps.org.au 